ENTREPRENEURSHIP AND SUSTAINABILITY ISSUES

ISSN 2345-0282 (online) http://jssidoi.org/jesi/

2021 Volume 8 Number 4 (June)

http://doi.org/10.9770/jesi.2021.8.4(7)
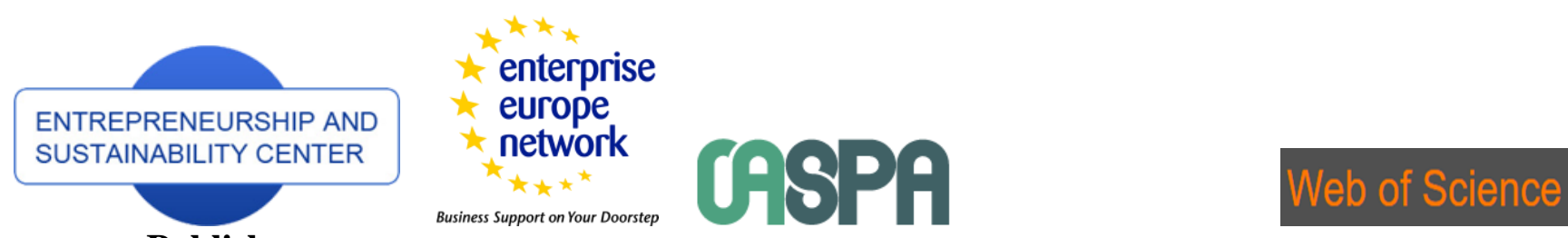

Publisher

$\underline{\text { http://jssidoi.org/esc/home }}$

Business Support on Your Doorstep

I Clarivate

Analytics

\title{
ROBOTIC PROCESS AUTOMATION IMPLEMENTATION, DEPLOYMENT APPROACHES AND SUCCESS FACTORS - AN EMPIRICAL STUDY*
}

\author{
Andrzej Sobczak \\ Warsaw School of Economics, Collegium of Economic Analysis, Niepodległości 162, 02-554 Warsaw, Poland \\ E-mail:sobczak@sgh.waw.pl
}

Received 15 September 2020; accepted 27 February 2021; published 30 March 2021

\begin{abstract}
An ever broader use of digital technologies which will lead to profound changes in the functioning of both individual entities as well as entire industries. These changes are referred to as digital transformation. Automation of business processes is a significant aspect of digital transformation. More and more entities (especially in such sectors as: banking, insurance, BPO/SSC, telecommunications) are implementing IT tools that are classified as part of the currently emerging RPA (Robotic Process Automation) category, where the term robot has a metaphorical meaning here - it is a particular type of software, and not a device. It should be emphasized that large scale robotic process automation cannot be viewed as an IT project. It is a business change project with a technical component, very frequently carried out outside the IT department by the company's business units. In the long term - along with the popularization of cognitive robotic process automation - it will lead to the growth of digital innovations at enterprises. The article attempts to answer four research questions: RQ1) what are the premises for the implementation of robotic process automation by enterprises, RQ2) how the implementation of robotic process automation is carried out from the organizational point of view, RQ3) in which areas of enterprise business operations is robotic process automation applied and RQ4) what factors determine the success of robotic process automation. The literature research method is used in the article and the results of surveys carried out among 238 Polish enterprises are presented. The results obtained allow us to conclude that the enterprises surveyed are only at the beginning of the mass scale robotic process automation, but due to the increasingly competitive environment, there will be no turning back.
\end{abstract}

Keywords: Robotic Process Automation; Business Process Management; Digital transformation; Digital innovations; Entrepreneurship

Reference to this paper should be made as follows: Sobczak, A. 2020. Determinants of Robotic Process Automation implementation, deployment approaches and success factors - an empirical study. Entrepreneurship and Sustainability Issues, 122-147. https://doi.org/10.9770/jesi.2021.8.4(7)

JEL Classifications: L26, O32, O33, Q55

Additional disciplines management and quality

\footnotetext{
* This research was funded by the support of the Fundation Centre for Studies on Digital Government project "Advanced aspects of business process automation".
} 


\section{ENTREPRENEURSHIP AND SUSTAINABILITY ISSUES}

ISSN 2345-0282 (online) http://jssidoi.org/jesi/

2021 Volume 8 Number 4 (June)

http://doi.org/10.9770/jesi.2021.8.4(7)

\section{Introduction}

As noted by M. Jarrahi, S. Zuboff's study "In The Age Of The Smart Machine: The Future Of Work And Power" was published already at the end of the 1980s, in which the author, applying an ethnographic approach, described in detail the impact of digital technology on the employees and their work. In spite of the rapid changes in technology over the recent decades, Zuboff's main observations with respect to computerization, and automation in particular, and its impact on work, are still largely relevant. In her opinion, automation means the use of technology to perform work faster and more efficiently, which will lead to profound changes in the labor market. Zuboff proposed that computer systems should be perceived as "smart machines", and her conceptualization was one of the first attempts to examine the transformational nature of IT with respect to work automation (Jarrahi, 2019). Six years later, in 1995, J. Rifkin presented a hypothesis that "we are entering a new phase in world history where fewer and fewer workers are needed to produce goods and services for all mankind" (Rifkin, 1994). The shrinking demand for manpower is due to the advances in process automation made possible by the use of the increasingly sophisticated information and telecommunications technologies. However, some researchers indicate that there is a tendency in the media to exaggerate the scope of replacing human labor with robots. This is demonstrated, among others, by the results of research (Eikebrokk, Olsen, 2020), as part of which the impact of robotic process automation on changes in the white-collar workers' employment level was analyzed. According to the above mentioned authors, robotic automation at the current stage of its implementation does not lead to workforce layoffs - most often the personnel ends up being transferred to perform other tasks. However, one should be aware of the fact that business process automation technologies, as a result of combining them with artificial intelligence, have more and more "power". This may result in profound changes in the employment structure in the future. In particular, automation will push employees out of certain jobs, and. at the same time, there will be a growing demand for workers with new competencies (Varghese, Kumar, 2017).

Robotic Process Automation is an area that is growing particularly fast at the moment, - both in terms of its application, as well as research. The concept is viewed in two different ways in the subject matter literature narrow and broad.

According to the narrow view, the term refers to a class of information technology tools used to automate business processes using software robots, where software robots are computer programs operating based on the predefined algorithms, used to automatically perform business processes or parts thereof. They usually imitate human labor, most often reproducing it faithfully. Robots are operating based on the preset algorithm, but more and more often they are enriched with certain elements of artificial intelligence, and, as a result, they are able to make more complex decisions and learn based on the data provided - both structured, as well as unstructured (Lacity, Willcocks, 2018). From the terminology point of view, a software robot is also referred to as a digital worker in the subject matter literature.

In the broader view of the concept, "robotic process automation" can be regarded as a particular type of an organizational and technological change the inherent part of which is the deployment of specific software (including cognitive software), ultimately leading to the formation of a hybrid workforce (Fersht et al., 2019), (Lacity, Willcocks, 2018), (Willcocks et al., 2020). Such an workforce is understood as a coherent ecosystem of software robots as well as human resources with specific skills and competences, performing specific business processes and processing specific data. The latter, broader understanding of the robotic process automation concept has been assumed for the purpose of this article. The adoption of such an understanding of robotic process automation leads to the viewing of actions related thereto not only from the technology point of view but also from the organizational and cultural perspective. 


\section{ENTREPRENEURSHIP AND SUSTAINABILITY ISSUES}

ISSN 2345-0282 (online) http://jssidoi.org/jesi/

2021 Volume 8 Number 4 (June)

http://doi.org/10.9770/jesi.2021.8.4(7)

Therefore, the topics discussed in the article fall within the thematic scope of the theoretical considerations and empirical research conducted as part of several sub-disciplines of the management science (Belez et al., 2019), in particular:

- Change management (sub-discipline: Strategic Management) - robotic process automation is considered in the article as a specific type of an organizational change that should be managed appropriately;

- Management in the robotic process automation environment (sub-discipline: Production, Services and Technology Management) - the management context in the robotic process automation environment is the main theme of the discussion presented in the article.

The objective of the article is to present - based on the literature studies - key robotic proces automation concepts and to verify such concepts based on the results of surveys conducted among Polish enterprises. In particular, the author will be looking for answers to the following research questions:

RQ1) what are the premises for the implementation of robotic proces automation by enterprises,

RQ2) how is the implementation of robotic process automation carried out from the organizational point of view,

RQ3) in which areas of enterprise business operations is robotic process automation applied,

RQ4) what factors determine the success of robotic process automation.

The rest of the article is structured as follows. Section two presents selected theoretical aspects of robotic process automation. Section three discusses the methodological and organizational aspects of the survey research conducted. Section four presents the results obtained and the discussion thereof. The study concludes with a summary and an outline of directions for future research.

\section{Theoretical background of Robotic Process Automation - selected aspects}

As presented in the first section, according to the narrow view, the term Robotic Process Automation refers to a class of information technology tools used to develop software robots that automate business processes or subprocesses, implemented using various IT systems (most often not integrated with one another). Robots developed using the RPA solutions are usually running on dedicated machines (physical or virtual) or in a cloud - private or public, performing most of the activities under the supervision of a human operator (while a robot can be started automatically, without human intervention). The human operator is also involved in handling exceptions and emergencies that may occur during tasks performed by robots built using the RPA tools.

RDA (Robotic Desktop Automation) and C-RPA (Cognitive Robotic Process Automation) tools - also known as I-RPA (Intelligence Robotic Process Automation) tools are very closely related to the RPA tools.

RDA is a category of software used to build robots that automate activities usually performed on a single work station (workstation) and operate at the graphical user interface level (typically using one of the variants of the "data scraping" technique - extracting data directly from the user interface). During the activities performed by a robot (whose launch is initiated by a human operator), created with the use of the RDA solutions, the robot can, if required, transfer control to the person supervising the given work station - so that he/she could make a decision that requires experience or a difficult to structure expert knowledge.

C-RPA is a category of software used to develop software robots typically used for the comprehensive robotic automation of complex business processes or sub-processes. Robots created with the use of the C-RPA solutions employ artificial intelligence mechanisms - in particular, machine learning, computer vision, natural language processing models. They usually run in the public cloud or on dedicated machines (physical or virtual) and perform most of the activities on their own (without or only with a minimal human operator participation). Their 


\section{ENTREPRENEURSHIP AND SUSTAINABILITY ISSUES}

ISSN 2345-0282 (online) http://jssidoi.org/jesi/

2021 Volume 8 Number 4 (June)

http://doi.org/10.9770/jesi.2021.8.4(7)

determinant is the ability to process unstructured data and acting not on the basis of the predetermined rules, but adapting to changes in the environment thanks to the learning mechanisms.

It has been assumed for the purpose of this article that all types of software robot development tools are collectively referred to as RPA, unless they are directly referenced to a specific tool category.

Researchers dealing with robotic process automation have identified a number of distinguishing features of software robots developed using the RPA tools (Aguirre, Rodriguez, 2017), (Anagnoste, 2018), (Lacity, Willcocks, 2017), (Willcocks, Lacity, 2016):

- they are used to automate selected sub-processes that make up the given process or even tasks logically extracted out of such a process, definitely less often to automate processes end-to-end;

- they are, first and foremost, used with respect to operational processes and business support processes, they are implemented less often in the direct customer service area (Chatbots, Voicebots or Taskbots are typically used in the latter case); attempts are currently underway to apply robotic process automation also in the manufacturing processes - software robots are combined, for example, with sensors (that are a part of the Internet of Things solutions) and image recognition using the OCR tools (see Kobayashi at el., 2019).

- they automate sub-processes or mass (large scale) operations (i.e. performed multiple times within the assumed time unit - e.g. within a month or a year), most often by faithfully reproducing actions carried out by an operator thus far;

- their use does not entail the need to optimize or reengineer processes that are being robotically automated (although it is recommended);

- they operate based on the preset algorithm implemented therein (reproducing routine activities), but cognitive robots already have capabilities to learn and draw conclusions based on incomplete information;

- they perform operations directly on the presentation layer, i.e. the GUI (Graphical User Interface), of the domain systems (such as, for example, ERP, CRM systems, e-commerce platforms, etc.) - the same way a human operator does it (although some RPA tools allow for performing operations directly on the robotically automated applications' database layer);

- they do not require creating of dedicated APIs (Application Programming Interface) to exchange data between applications (although some RPA tools provide such options);

- they do not require programming in the classic sense (although some vendors provide such an option) instead of writing a robot's code (strong coding), the robot is created in a dedicated tool using predefined graphic components (providing specific functionalities), which are then configured by providing specific parameters or recording actions (e.g. clicks) performed by a human operator; various tools provide diverse functionalities in this respect - e.g. recording of activities performed in a web browser (web recording), recording of activities performed on the user's workstation (desktop recording), recording of terminal sessions (terminal session recording);

- they use business logic that constitutes an integral part of the applications that a software robot will be working with, which eliminates the problem of reproducing such logic within the robot itself;

- they do not require a change in the code of the applications that the robot is interworking with, and therefore no knowledge of the internal structure of the individual applications is required, which is very important in case of the legacy systems;

- all operations performed by the robot can be recorded in the form of the so-called event logs, which can then be analyzed (for example, using the Process Mining tools).

It is also important to outline how the RPA tools are positioned in relation to other classic business process automation methods - such as workflow systems or BPMS (Business Process Management System) tools (Shaw at el., 2007). It can be assumed that both RPA, as well as the above mentioned classic solutions, have a common 


\section{ENTREPRENEURSHIP AND SUSTAINABILITY ISSUES}

ISSN 2345-0282 (online) http://jssidoi.org/jesi/

2021 Volume 8 Number 4 (June)

http://doi.org/10.9770/jesi.2021.8.4(7)

set of goals: to increase efficiency and minimize the costs of performing business processes, while ensuring the highest quality of the products delivered by such processes. These goals are, however, achieved using completely different means. The implementation of workflow or BPMS solutions involves altering of the processes. Introducing changes thereto after the completion of their implementation often entails the need to carry out programming work, which requires time and appropriate IT competences. The RPA solutions are the opposite of this. Their suppliers strive to make them intuitive to use so that the representatives of business units could handle operating them on their own, so that they are able to create robots on their own without the support or with minimal support of the IT departments. This is usually done in dedicated teams that constitute a Center of Excellence. Additionally, the implementation of the RPA tools does not require changes in the IT systems already running in the company. This significantly reduces the time required for their implementation, which also translates into lower costs and a lower risk of failure. An in-depth analysis of approaches to process automation based on the classical method and with the use of the RPA tools is presented in (Stolpe at el., 2017).

Despite the fact that robotic process automation has been very well received by many enterprises, more and more often some specialists are beginning to make comments on this approach. The opinion of P. Fersht, who is considered to be the author of the term Robotic Process Automation, is particularly important. He notes that at many companies there has been a phenomenon of misunderstanding or even deliberate denial of the idea on which the original concept of robotic process automation was based. Enterprises have used this approach to automate the "old way of operating", rather than using it as a lever to actually reengineer business processes (Fersht at al., 2019). According to the survey conducted in 2019 by HfS Research among 590 leaders from the group of the world's largest 2000 companies, only $13 \%$ of organizations managed to scale the implementation of the robotic process automation tools. The authors emphasize that the majority of organizations implementing RPA "are still tweaking small projects, piecemeal tasks and broken processes. Most companies are not even close to introducing any kind of enterprise wide automation" (Fersht, et al., 2019). At the same time, robotic process automation is a natural direction of enterprise automation, but it must be viewed as a holistic undertaking where various tools (including those using artificial intelligence and advanced data analysis) and organizational change management mechanisms are combined.

Therefore, the author of this compilation proposes the following - broader than just technological - approach to robotic process automation: it is a construct covering the process, content and result of an organizational change, the core of which is robotic process automation carried out with the use of software robots. Where:

- process perspective refers to the activities, tools, organizational structures and human resources required to prepare organizations and processes for robotic automation, and to build, deploy, maintain and develop software robots; based on this approach robotic automation may be a continuous process;

- content perspective refers to the processes to be robotically automated and the software robots being developed;

- result perspective refers to the products of the robotic automation process - the created organizational structures responsible for robotic automation, implemented solutions used for robotic automation, robotically automated processes and the effects obtained as a result thereof.

Adopting such an understanding of robotic process automation requires considering activities related thereto not only from the technological perspective, but also - and perhaps even first and foremost - from the management, organizational and cultural perspective. As it is presented in (Lacity, Willcocks, Craig, 2017, p. 13), robotic automation is not an IT undertaking. It is a business venture with a small IT component - 98\% of the undertaking is related to the business rules, which means that, first of all, business process experts are needed to carry out such a project. Therefore, in a broader sense, robotic process automation cannot be equated only with the implementation of a project involving the deployment of an RPA class tool and developing software robots using 


\section{ENTREPRENEURSHIP AND SUSTAINABILITY ISSUES}

ISSN 2345-0282 (online) http://jssidoi.org/jesi/

2021 Volume 8 Number 4 (June)

http://doi.org/10.9770/jesi.2021.8.4(7)

such a tool. Instead, it is necessary to consider it in the context of the implementation of a portfolio of projects (that are the carriers of change), and then to continuously maintain and further develop the changes implemented.

Companies are making decisions to deploy RPA class solutions - incurring material capital expenditures - based on the number of benefits that can be achieved as a result of such deployments. The most important ones include: reducing the costs of performing business processes, improving capabilities to carry out such processes without increasing headcount, enhancing employee experience by freeing personnel from performing the most mundane, routine activities, improving quality of products/services provided - as a consequence of minimizing the number of errors made by humans in the business processes carried out, or finally, increasing the number of innovations introduced by organizations by providing the ability to quickly prototype new products/services that require integrating various systems without the need to engage IT departments (Anagnoste, 2018), (Asatiani, Penttinen, 2016), (Willcocks, Lacity, 2016).

An additional factor impacting the current rise in popularity of the RPA solutions is the social and economic situation associated with the COVID-19 coronavirus pandemic. For a number of companies, robotic process automation allows not only to reduce costs, but also enables to ensure continuity of the ongoing processes.

It is also worth noting that a deployment of the robotic process automation tools can be viewed as the foundation for creating digital innovations, since innovations of this type can be understood as a) digital technologies, b) the result generated from the use of such technologies, c) the way processes are implemented using such technologies, changing the nature, structure or method of delivering products/services (to external and internal customers - the author's note) or the way value is created for such customers (Berman, 2012),(Nambisan at al., 2017). As a consequence, this my lead to the transformation of entire industries. Starting with the presented determinants of digital innovation, an assertion can be made that: (1) robotic process automation tools are classified as digital technologies, (2) robotic process automation - in particular carried out with the use of the CRPA tools - enables the creation of completely new products (that would be unprofitable or impossible to deliver based on the traditional enterprise operations methods), (3) robotic process automation changes the way services are delivered (in particular internal services - provided between the individual departments of a company), (4) robotic process automation may bring about the transformation of entire industries (this is applicable, for example, to the BPO/SSC industry (Suri at al., 2017), (Willcocks at al., 2017).

At the same time, there is a high probability of a number of risk factors materializing during robotic process automation. The most important of them include: a) risk of the wrong perception of robotic process automation viewed only through the prism of activities aimed at cutting the costs related to human resources, $b$ ) risk related to the wrong choice of the robotic process automation model at the given organization, c) risk related to the wrong approach to change management in the robotically automated processes, d) risk related to the resistance of the personnel involved in the processes to be robotically automated, e) risk of a competence gap (Lacity, Willcocks, 2017).

It should also be noted that the future of work environment in many industries is not only its digitization, but also its hybrid nature, where the hybrid nature is understood here as creating of the conditions enabling close cooperation between robots and humans. Such cooperation will be the source of a number of challenges and risks - managerial, ethical, cultural (Malshika et al., 2019).

\section{Research objective and methodology}

In order to answer the research questions presented in the introduction to the article, the author prepared and conducted a survey research in the April - June 2020 time frame. It was composed of two stages - the pilot stage and the main survey. As part of the pilot stage, a questionnaire on robotic process automation was created and 


\section{ENTREPRENEURSHIP AND SUSTAINABILITY ISSUES}

ISSN 2345-0282 (online) http://jssidoi.org/jesi/

2021 Volume 8 Number 4 (June)

http://doi.org/10.9770/jesi.2021.8.4(7)

verified. The survey questionnaire was verified by way of a pilot survey conducted among 15 enterprises representing industries that were planned to be included in the main survey. The subject of the verification was the level of understanding by the respondents of the questions included in the questionnaire, as well as the completeness thereof. As a result of the completed pilot stage, modifications were introduced in the questionnaire itself - four questions were significantly altered, and the wording of another three questions was made more precise. Due to the changes in the questionnaire, the research material collected during the pilot stage was not used in the further research procedure. As part of the main stage of the research, the key survey - from the point of view of the entire research procedure - was conducted. The selection of enterprises for the survey was deliberate an enterprise had to declare the deployment of at least one software robot in the production environment (developed with the use of the RPA, RDA or C-RPA class tool).

The CAWI (Computer Assisted Web-Interviews) technique was used to carry out the survey, where the respondent individually completed the electronic version of the questionnaire available on-line. It is currently one of the most frequently used polling techniques. As Smith and Kim point out, CAWI is a part of the Computer Assisted Survey Information Collection (CASIC) group of techniques, that are a part of the broader group of Computer Assisted Data Collection (CADAC) techniques (Smith, Kim, 2015). Several factors were behind the author's choice of this research technique. The use of the questionnaire in the electronic form was, first and foremost, aimed at obtaining possibly largest number of collected surveys (the survey was addressed to a specific group of the respondents for whom on-line tools are a natural work environment), shortening the time it took to conduct the survey, enabling the respondents to provide answers at a time convenient for them and cutting the cost of conducting the research work, while, at the same time, maintaining a high degree of completeness and quality of the answers (possible to obtain thanks to the introduction of validation rules for the individual fields of the questionnaire and validation across the individual fields; such validation was applied due to the problems that had occurred during the pilot survey carried out with the use of the paper version of the questionnaire). Significant arguments in favor of choosing the CAWI technique also included the ease and convenience of filling in of the questionnaires by the respondents, as well as the reduction of the interviewer's influence on the answers given by the respondents (such influence could occur in case of the face-to-face survey). The final argument for choosing this research technique was the coincidence of the timing of the survey with the pandemic situation, and the resulting limitations of direct communications with the respondents.

The answers obtained were subjected to additional verification, beyond just checking that all of the mandatory fields in the questionnaire had been filled. In case of ambiguity or inconsistency in the answers, the respondent was contacted by e-mail (the provision of the business e-mail address of the person completing the questionnaire had been a prerequisite for including the given questionnaire in the research pool) and asked to provide explanations by e-mail, or in the event that there were more ambiguities - a telephone conversation was arranged or the teleconference tools - Zoom and MS Teams - were used.

The author made a conscious decision not to engage a survey company in the research. It is true that such a method of conducting a survey would provide a number of benefits (among others, the ability to directly clarify any ambiguities that the respondents faced when filling in the questionnaire, increased motivation of the respondent to complete the questionnaire, which translates into a higher rate of survey returns), but it also has a number of limitations. First of all, it significantly extends the time and increases the costs of conducting a survey, and also generates the risk of diversified training of the individual interviewers, which leads to the possibility of inconsistencies occurring in the explanations provided to the respondents. Face-to-face surveys with the use of interviewers are advisable when dealing with questionnaires containing a large number of open-ended questions (which was not true in case of the questionnaire used by the author, as practically all of the questions were closedended) and in case it is necessary to take actions aimed at forcing answers to all of the questions (this was not true in case of the questionnaire used by the author, as the system applied to develop the questionnaire enabled imposing of the obligation on the respondent to provide an answer). 


\section{ENTREPRENEURSHIP AND SUSTAINABILITY ISSUES}

ISSN 2345-0282 (online) http://jssidoi.org/jesi/

2021 Volume 8 Number 4 (June)

http://doi.org/10.9770/jesi.2021.8.4(7)

Ultimately, a total of 238 questionnaires (out of 294 sent) were qualified for the analysis, with each of them meeting the following set of conditions:

- questionnaire was completed by a representative of a company from an industry that was included in the study (23 questionnaires were rejected due to non-compliance with this condition);

- all mandatory fields were completed (all questionnaires met this condition); this way the author wanted to avoid averaging the respondents' answers, which is a typical procedure when such situations occur;

- all validation rules were complied with (26 questionnaires were rejected due to non-compliance with this condition);

- all of the doubts regarding the completion of the questionnaire were explained by the author by e-mail or during the interview (7 questionnaires were rejected due to non-compliance with this condition).

The questionnaire used during the survey included 34 questions. The author decided to use diverse types of questions in the questionnaire (in the main part of the questionnaire and in the respondent's particulars (demographics) section):

- 18 single-choice cafeteria questions,

- 3 multiple-choice cafeteria questions, including 1 closed-ended and 2 semi-open-ended questions;

- 12 questions with a 7 point Likert scale,

- 1 open-ended question (in the respondent's particulars (demographics) section - it related to the respondent's business e-mail).

The questions in the main part of the questionnaire were related to the conditions for implementing robotic process automation at an enterprise, the status and scope of robotic process automation, the approach to developing and maintaining software robots, combining robotic process automation with other process automation tools, factors determining the success of robotic process automation, the impact of robotic process automation on the business model of the enterprise and the enterprise management system.

A certain number of questions were included in the questionnaire as control variables. On one hand, the goal of this step was to take into account those attributes or characteristics of the environment/industry that may constitute alternative explanations of the results obtained. Such variables are related to the intensity of competition, the dynamics of the technological environment, the dynamics of the market and regulatory environment, as well customer attitudes. The remaining control variables were related to such issues as:

- enterprise size measured by the number of employees,

- enterprise size measured by revenue,

- enterprise sector.

In addition, a filtering question was introduced - its purpose was to separate the enterprises that had at least one software robot deployed in the production environment from those companies that could not demonstrate such deployment (in such case their answers were not included in the research pool).

A seven point (not a five point) Likert scale was used in the questionnaire, which was supposed to increase the accuracy of the measurement. Such a structure of questions is more and more often recommended in management sciences. However, despite the legitimacy of using the Likert scale with an extended number of response categories in empirical research - i.e. a 7 point scale instead of a 5 point scale, after the preliminary data analysis had been conducted, the decision was taken to combine two variants of answers in the categories appearing at the opposite ends of the scale. In other words, two variants of answers had been aggregated into categories that were later named "Strongly disagree"/"Strongly agree". On both ends of the scale the aggregation covered two categories, expressed on the original 7 point scale as " $1=$ Strongly Disagree" and " 2 = Disagree". These 


\section{ENTREPRENEURSHIP AND SUSTAINABILITY ISSUES}

ISSN 2345-0282 (online) http://jssidoi.org/jesi/

2021 Volume 8 Number 4 (June)

http://doi.org/10.9770/jesi.2021.8.4(7)

categories corresponded to the answers related to the respondents' negative attitudes. On the other hand, on the opposite end of the scale, two categories corresponding to the respondents' positive attitudes were aggregated: "6 $=$ Agree" and "7 = Strongly agree". Finally, after the data had been converted, the new categories of the respondents' answers were assigned the following names as the components of the 5 point scale: "1 = Strongly disagree", "2 = Rather disagree", "3 = Hard to say", "4 = Rather agree", "5 = Strongly Agree". The low percentages of answers in the two categories on the 7 point scale (" $2=$ Disagree" and " $6=$ Agree") were the main reasons for the above combining of the variables, as in the original survey there had been some kind of artifacts in the answers given by the respondents

The research covered companies from the following industries: banking and insurance, other finance (apart from banking and insurance), professional business services (based on the following split: Business Process Outsourcing (BPO) and Shared Services Centers (SSC)), e-commerce, trade, logistics, media, advertising and entertainment, health care (including pharma), manufacturing, telecommunications, utilites (including energy, gas, heat). The respondents included mainly representatives of shared services centers (SSC), banking and insurance, manufacturing/production and professional services centers for business (BPO) - see fig. 1. According to the literature research carried out by the author, companies operating in these industries are the world's leaders in robotic process automation.

IT (including the RPA tool suppliers) and consulting companies were deliberately not included in the study, as the thematic scope covered by the survey was primarily related to the intra-organizational issues of robotic process automation. The research also did not cover public administration units, as such entities have not yet begun to apply robotic process automation on a larger scale. The author monitored the implementations of robotic process automation at Polish organizations. At the time the study began, only two municipality offices (city halls) reported robotic process automation activities, and a few more were just getting ready for such projects; also there are few references to deployments at such units in the subject matter literature, - see for example (Nauwerck, Cajander, 2019). 


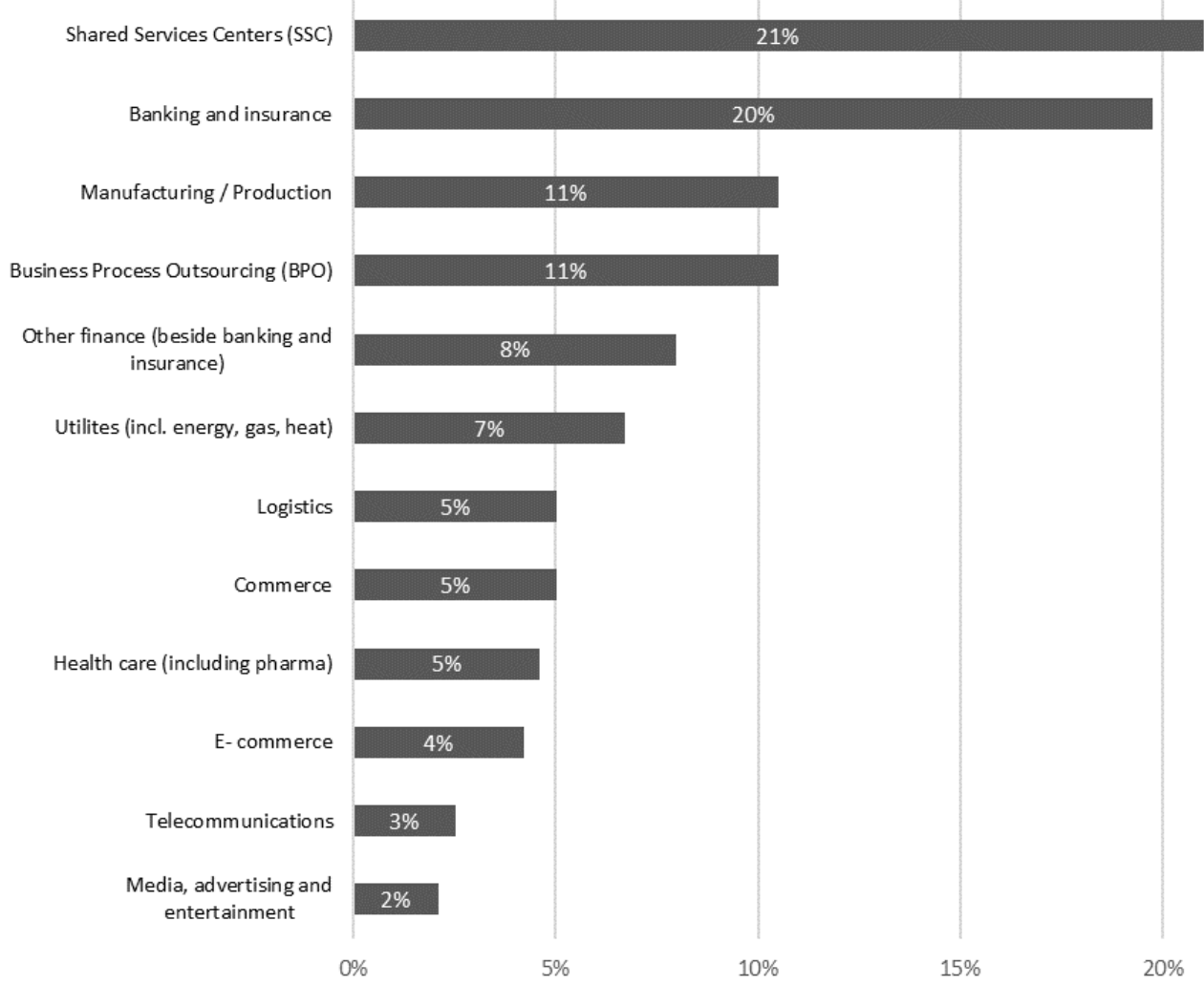

Fig. 1. Industries included in the research $[\mathrm{N}=238]$ Source: compiled on the basis of own research

As mentioned earlier, 238 enterprises from all over Poland took part in the survey. Based on the analysis of the respondents' composition (see fig. 2), it can be noted that large enterprises (i.e. with more than 250 employees) were a dominant group - they accounted for $75 \%$ of the entire sample. The small and medium-sized enterprises i.e. those employing up to 250 people - were a minority - representing $25 \%$ of the total.

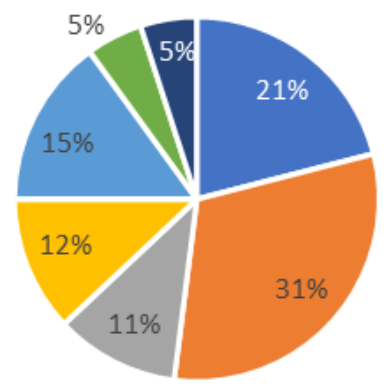

$$
\begin{aligned}
& \text { - }>=5000 \text { persons (FTEs) } \\
& \text { " } 1000-4999 \text { persons (FTEs) } \\
& \text { " } 500-999 \text { persons (FTEs) } \\
& \text { " } 250-499 \text { persons (FTEs) } \\
& \text { - } 100-249 \text { persons (FTEs) }
\end{aligned}
$$

Fig. 2. Size of enterprises taking part in the survey [ $\mathrm{N}=238]$ Source: compiled on the basis of own research 
When analyzing the results of the respondents' assessment of the environment in which their companies are operating (see fig. 3) it should be noted that it is extremely competitive (58\% of the respondents indicated that the competition in their industry is very fierce), and customers are demanding (as many as 64\% of the respondents indicated that customers in their industry expect very high quality of products/services provided). In addition, according to the respondents, the legal (including regulatory) and technological changes are taking place very rapidly (this is applicable to a lesser extent to the technological changes).

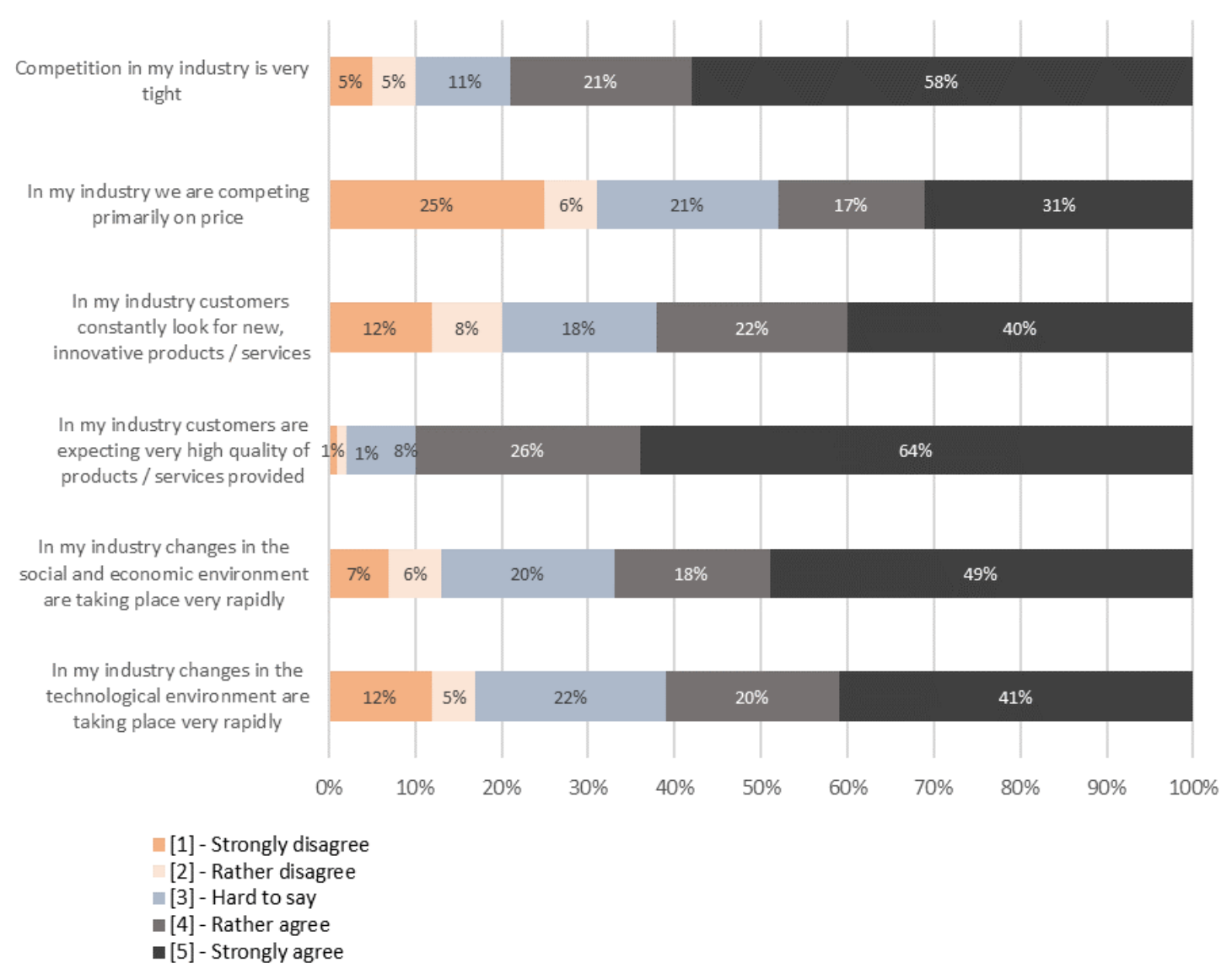

Fig. 3. Characteristics of the enterprise's environment $[\mathrm{N}=238]$ Source: compiled on the basis of own research

The respondents were mainly the managers of units/leaders of teams dealing with robotic process automation $36 \%$. Among the balance of the respondents, the managers/directors responsible for robotic process automation were a large group - accounting for $29 \%$ of the total (see fig. 4 ). 


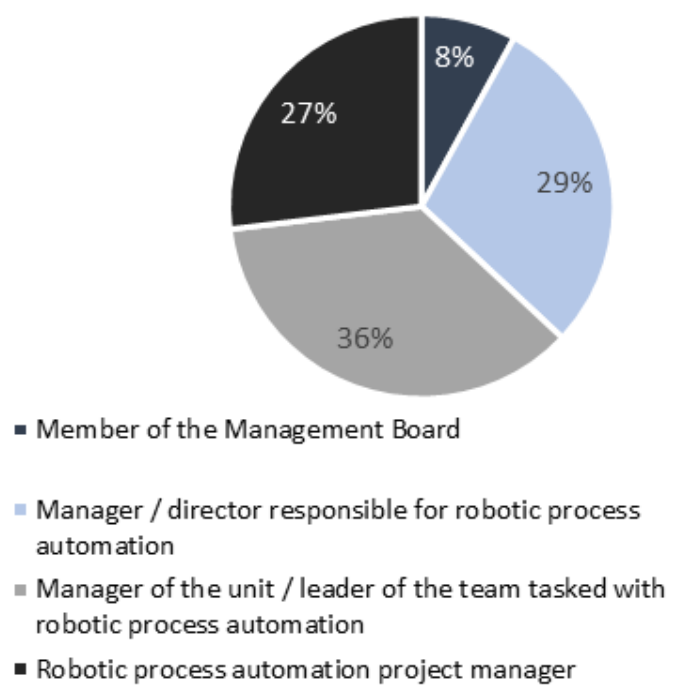

Fig. 4. Position of the respondents [ $\mathrm{N}=238]$

Source: compiled on the basis of own research

People with limited experience in RPA related activities (between 1 and 2 years - representing 34\% of the total), and even with very limited experience (less than 1 year - accounting for $30 \%$ of the sample) were a dominant group among the respondents (see fig. 5).

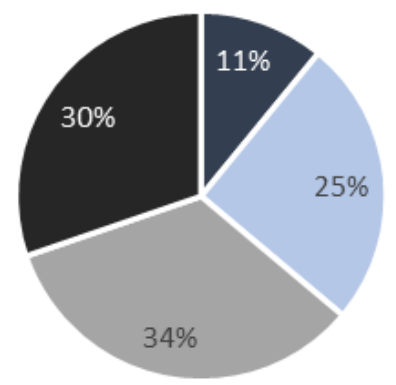

- 5 and more years = $3-4$ years $=1-2$ years $:<1$ year

Fig. 5. Respondents' professional experience in robotic process automation $[\mathrm{N}=238]$

Source: compiled on the basis of own research

Such a composition of the respondents stems from the fact that for most of the people (as well as the enterprises surveyed) robotic process automation is a new subject. Previous analyses carried out by the author demonstrate that pilot implementations of robotic process automation projects in Poland began at the turn of 2017/2018, and only 2019 saw the establishment of this method of business process automation on the market.

\section{Results and discussion}

As indicated by the research conducted, robotic process automation is a new subject for the majority of enterprises (see: fig. 6). Nearly $1 / 3$ of the respondents have been implementing robotic process automation for less than a year. The same number of the respondent organizations have been implementing robotic process automation for 1 to 2 years. Companies that have been implementing robotic process automation for more than 3 years (17\%) are a minority among the enterprises surveyed. According to the author, these results indicate a very 
preliminary phase of the robotic process automation implementation at the entities surveyed and their very low maturity in this respect.

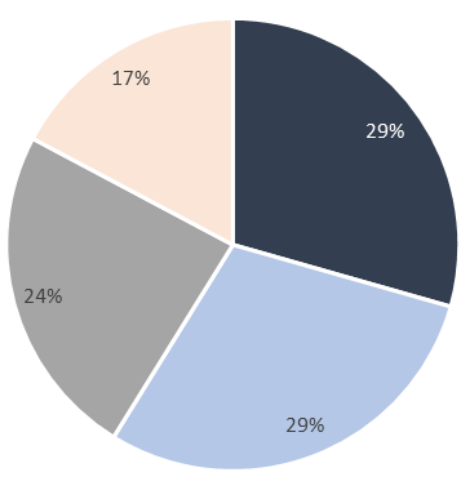

- Less than a year $=$ Between 1 and 2 years $=$ Between 2 and 3 years $=$ More than 3 years

Fig. 6. Time enterprises have been implementing robotic process automation for $[\mathrm{N}=238]$

Source: compiled on the basis of own research

The time robotic process automation has been implemented for in the context of enterprise size (based on the number of employees) was also analyzed. Table 1 shows that large and very large enterprises were first to commence deploying robotic process automation solutions. On the other hand, small and medium-sized enterprises are just beginning to implement this approach.

Table 1. Analysis of the time robotic process automation has been implemented for versus the grouping variable "Enterprise headcount"

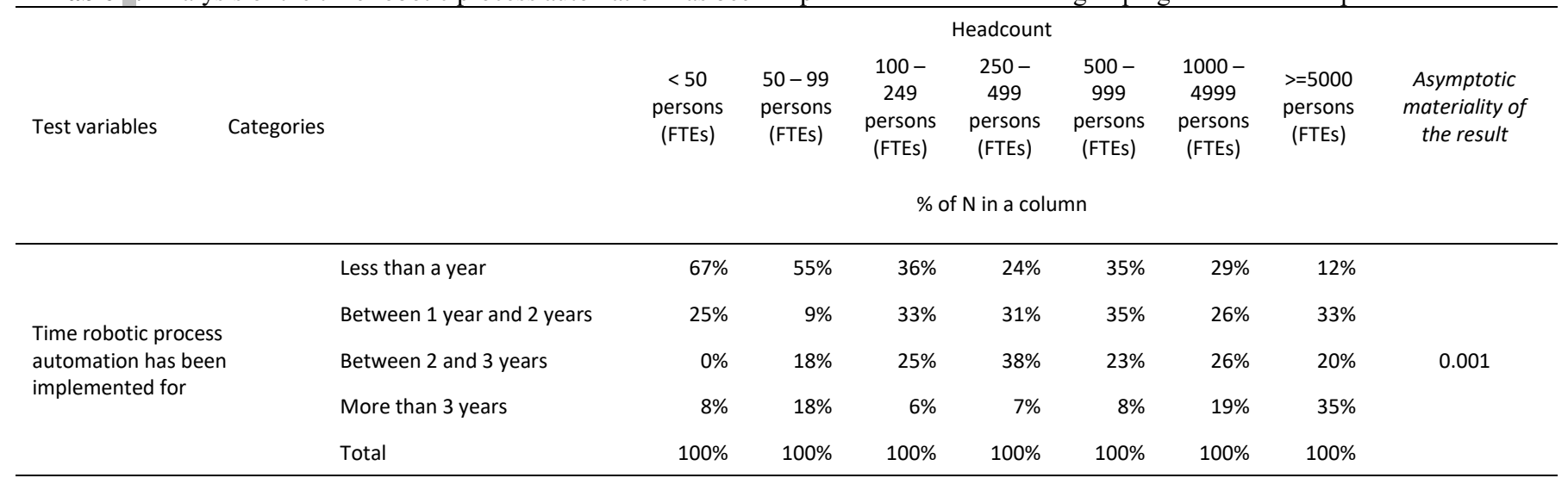

Key: Grouping variable: Enterprise headcount. Adopted materiality level (0.05). The result below 0.05 shows the differences in the distributions of individual test variables due to the adopted grouping variable and variable distributions

Source: compiled on the basis of own research

As shown in fig. 7, the vast majority of the organizations surveyed have only 1 to 4 software robots deployed in the production environment (regardless of their individual types). Such a small number demonstrates that the organizations surveyed are at the initial stage of implementing robotic process automation. 


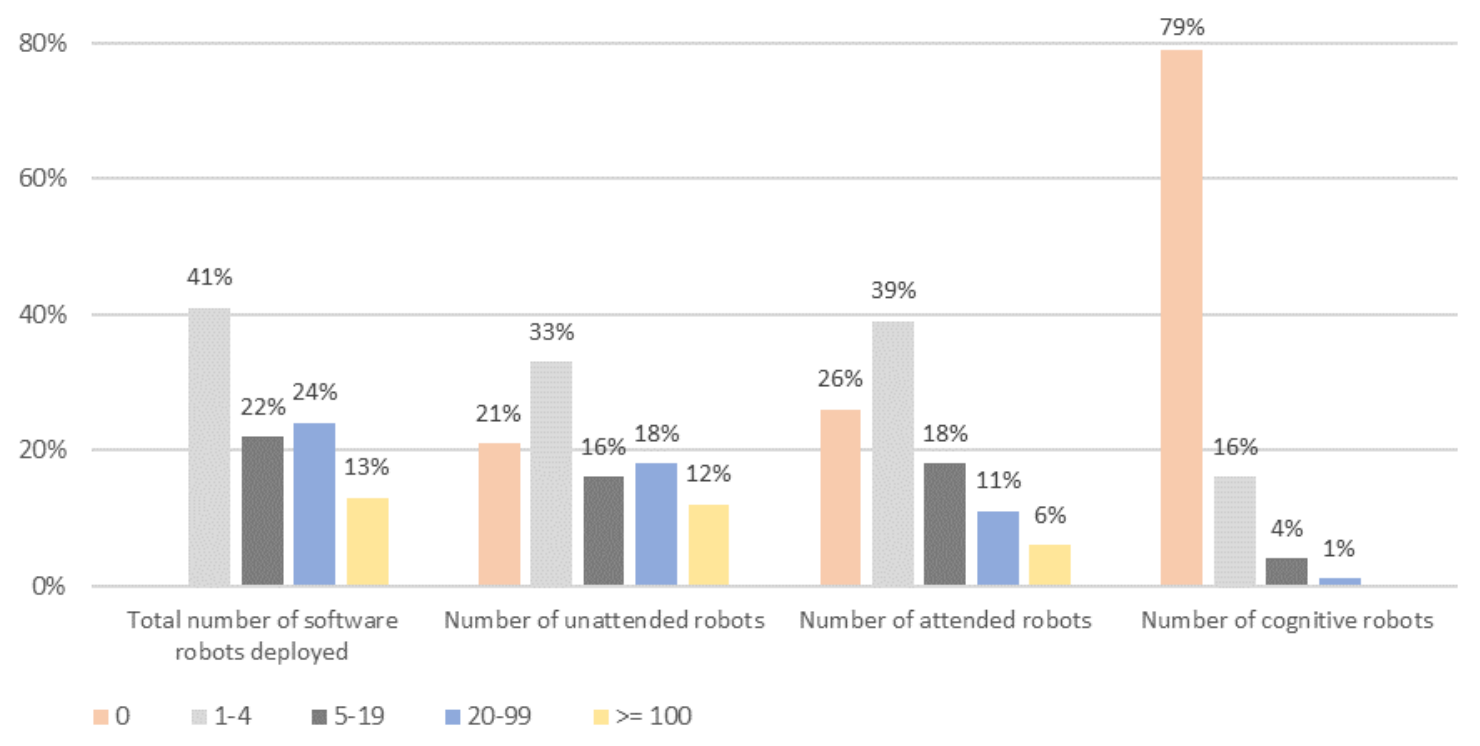

Fig. 7. Total number of software robots (attended, unattended, cognitive robots) deployed by enterprises [N $=238]$ Source: compiled on the basis of own research

When analyzing the number of the individual types of robots' (attended, unattended, cognitive) deployments at the enterprises surveyed, it can be seen that a relatively small number of organizations (21\%) have cognitive robots, of which the vast majority of enterprises have only 1 to 4 robots of this type. This demonstrates a very low level of intelligent robotic automation at these companies. The analysis of the classic robots' deployments attended (usually built with the use of the RDA class tools) and unattended (usually built with the use of the RPA class tools) - indicates that only $12 \%$ (attended robots) and $6 \%$ (unattended robots) of the respondents stated that they had 100 or more robots deployed (as outlined in the literature, this is a commonly assumed threshold above which it is assumed that robotic process automation is carried out on a mass scale). At the same time, as many as $33 \%$ and $39 \%$ of the respondents, respectively, indicated that their enterprises use between 1 and 4 robots attended and unattended (see fig. 7). In practice, this means that single processes or parts thereof are robotically automated at those companies.

Regarding factors behind the implementation of robotic process automation by a company (see: fig. 8), the option "Seeking to cut the company's operating costs" was chosen by nearly $78 \%$ of the respondents, who answered "Strongly agree", while $13 \%$ checked "Rather agree" (in total, the option to seek cost reductions was chosen by $91 \%$ of the respondents - the sum of these two response categories). On the other hand, only $4 \%$ strongly disagreed with this determinant of robotic process automation. The respondents also indicated seeking to relieve employees from performing routine activities as part of their work as a goal (in total, $88 \%$ of the respondents, the sum of the answers "strongly agree" and "rather agree" ), which reveals the respondents' strong motivations to robotically automate processes in order to improve the employee experience. These results are in line with the literature research carried out by the author. It is also worth noting that one of the factors behind implementing robotic process automation is seeking to increase the company's innovations (it is indicated by $87 \%$ of the respondents in total, the sum of the answers "Strongly agree" and "Rather agree"). This aspect of robotic process automation has thus far been relatively little exposed among researchers. It has been assumed that robotic automation is, first and foremost, applied in the support processes that are not innovative in nature. 
ENTREPRENEURSHIP AND SUSTAINABILITY ISSUES

ISSN 2345-0282 (online) http://jssidoi.org/jesi/

2021 Volume 8 Number 4 (June)

http://doi.org/10.9770/jesi.2021.8.4(7)

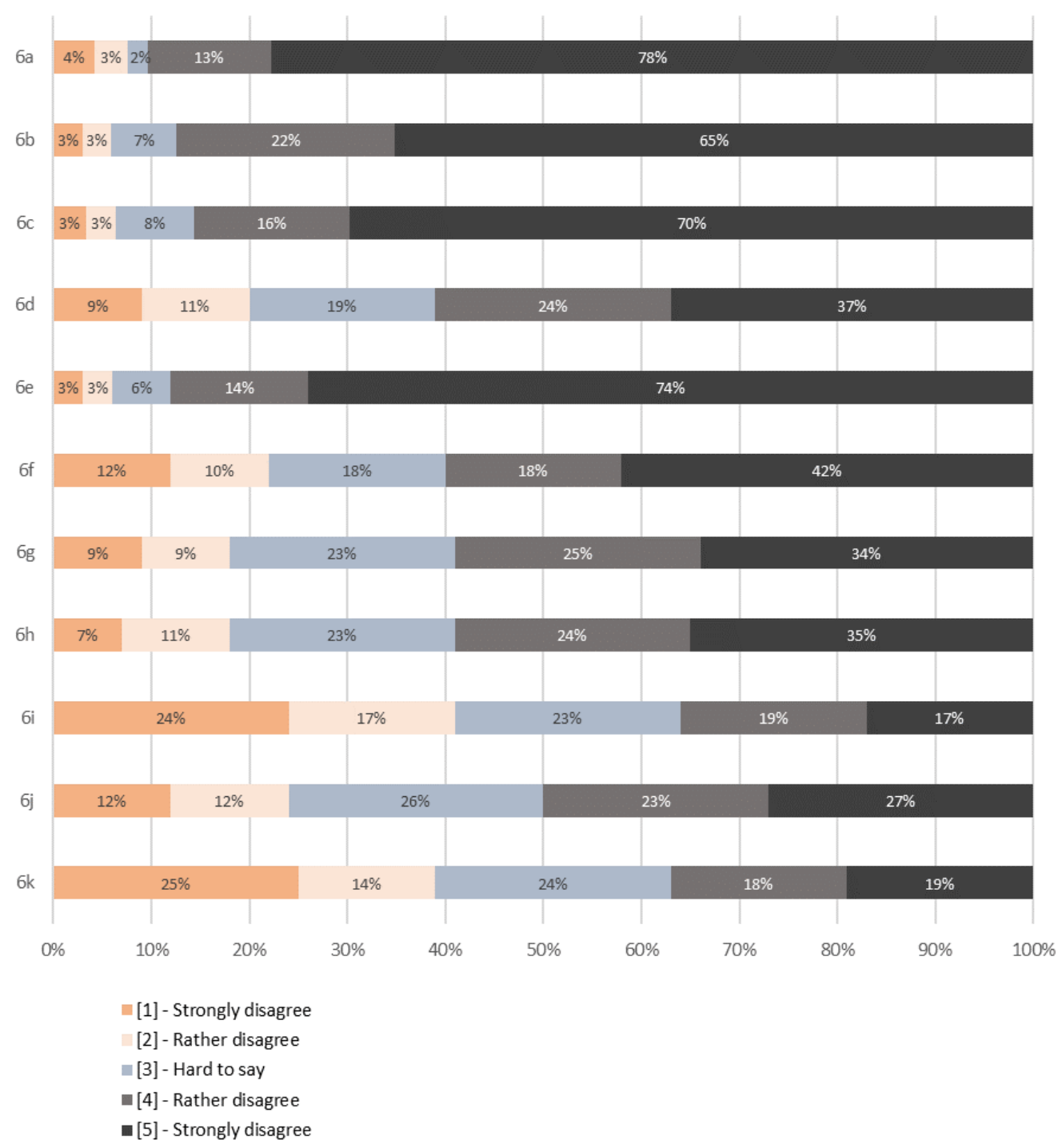

Key: Central measure (Median - ME) 50/50 of the distribution of answers for the individual items in the descending order: $6 \mathrm{a}=$ Seeking to cut the company's operating costs, $6 \mathrm{~b}=$ Seeking to increase the company's innovations, $6 \mathrm{c}=$ Seeking to boost employee productivity, $6 \mathrm{e}=$ Seeking to relieve employees from performing routine activities $(\mathrm{ME}=5.0=$ Strongly agree). $6 \mathrm{~d}=$ Seeking to reduce negative effects related to staff turnover, $6 \mathrm{f}=$ Seeking to liquidate workforce overtime, $6 \mathrm{~g}=$ Seeking to react faster to changes in the company's environment, $6 \mathrm{~h}=$ Seeking to improve customer experience, $6 \mathrm{j}=$ Seeking to minimize problems that occur as IT systems evolve (the so-called legacy systems syndrome) $(\mathrm{ME}=4.0=$ Rather disagree $) .6 \mathrm{i}=$ Following the activities carried out by the competitors, $6 \mathrm{k}=$ Not very effective IT department of the company, not keeping up with business needs $(\mathrm{ME}=3.0=$ Hard to say).

Fig. 8. Factors that determine the implementation of robotic process automation by a company [N=238] Source: compiled on the basis of own research

Considering the surveyed enterprises' approaches to developing software robots (see: fig. 9), it can be noted that the most common formula is based on the Center of Excellence - 46\% in total, while the least frequently used form is the involvement of the IT department in such projects (17\%). These results are in line with the literature research which indicates that robotic process automation should be classified as "lightweight IT", implemented mainly by the business units (Stolpe et el., 2017). 


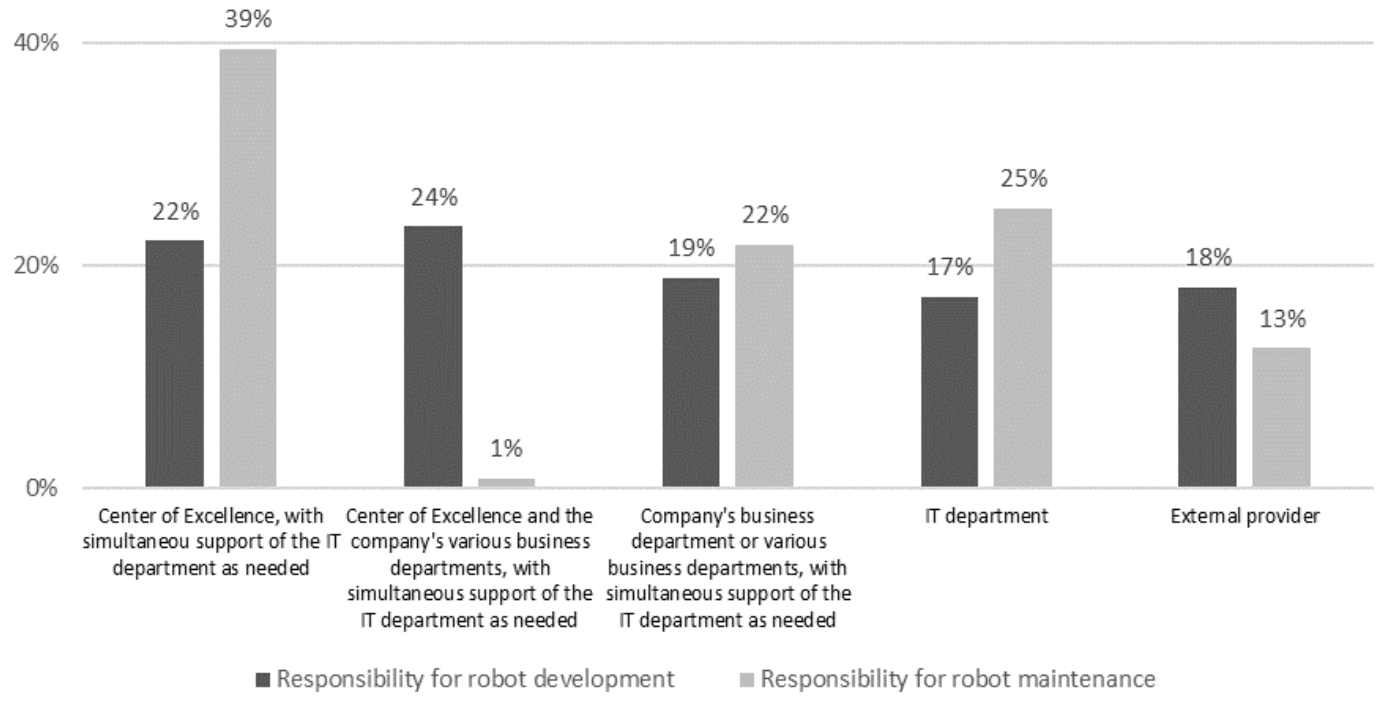

Fig. 9. Models of approaches to developing software robots [ $\mathrm{N}=238]$

Source: compiled on the basis of own research

The vast majority of the enterprises surveyed implement robotic process automation in the form of a series of small steps $(66 \%$ of the respondents indicated this method, versus $34 \%$ of the answers pointing to robotic process automation implemented as a large undertaking). The scope of robotic process automation is most often fragmentary in nature - usually covers 1-2 processes in a selected business area (see fig. 10), which may demonstrate that the companies surveyed are only just researching the capabilities of RPA or approaching it very cautiously. At the same time, it is worth noting that as many as $31 \%$ of the organizations surveyed view robotic process automation as a comprehensive undertaking - they have implemented or are planing to implement it in as many business areas as possible. From this point of view, robotic processs automation is becoming a fully fledged way to implement digital transformation.

When analyzing the results obtained, it is necessary to emphasize the need to develop and implement an effective governance model for robotic process automation at an enterprise. This is highlighted by D. Kedzior and E. Penttinen in their work. They are of the opinion that this is a prerequisite for the ability to effectively scale robotic process automation in the enterprise (Kedziora, Penttinen, 2020). 


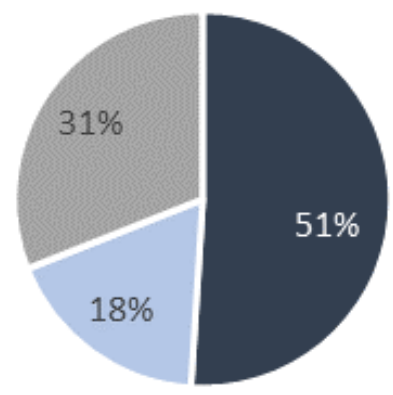

\footnotetext{
- 1-2 processes in a selected business area

$=1$ business area

n As many business areas as possible
}

Fig. 10. Scope of robotic process automation at enterprises $[\mathrm{N}=238]$

Source: compiled on the basis of own research

The scope of robotic process automation at an enterprise in the context of its size (based on the number of employees) was also analyzed. Table 2 shows that enterprises employing 1000 and more people approach robotic process automation in a holistic manner, which may also stem from the fact that the potential for robotic process automation is greatest at such companies.

Table 2. Analysis of the scope of robotic process automation versus the grouping variable "Enterprise headcount"

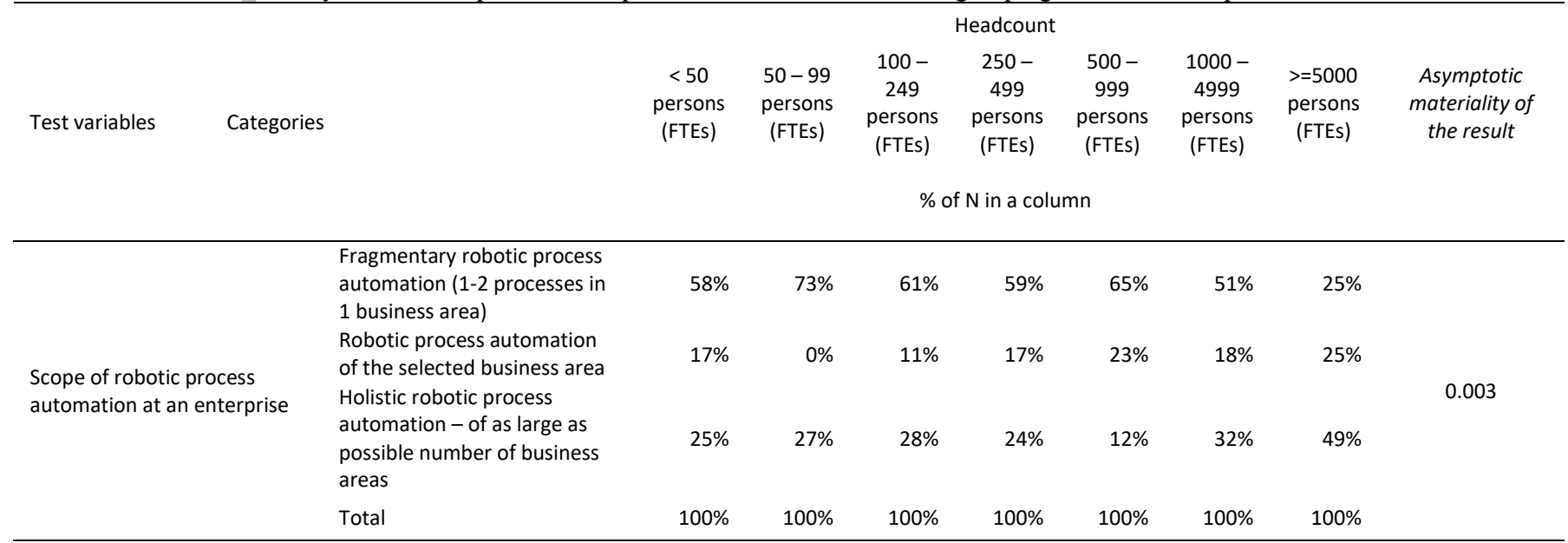

Key: Grouping variable: Enterprise headcount. Adopted materiality level (0.05). The result below 0.05 shows the differences in the distributions of individual test variables due to the adopted grouping variable and variable distributions

Source: compiled on the basis of own research

As shown in fig. 11, the implementation of robotic process automation is usually preceded by small (as indicated by $62 \%$ of the respondents) and medium scale changes ( $48 \%$ of the respondents) in the processes. These results are in line with the literature research conducted. In a relatively small number of cases $(11 \%)$ the changes in robotic processes are profound. 


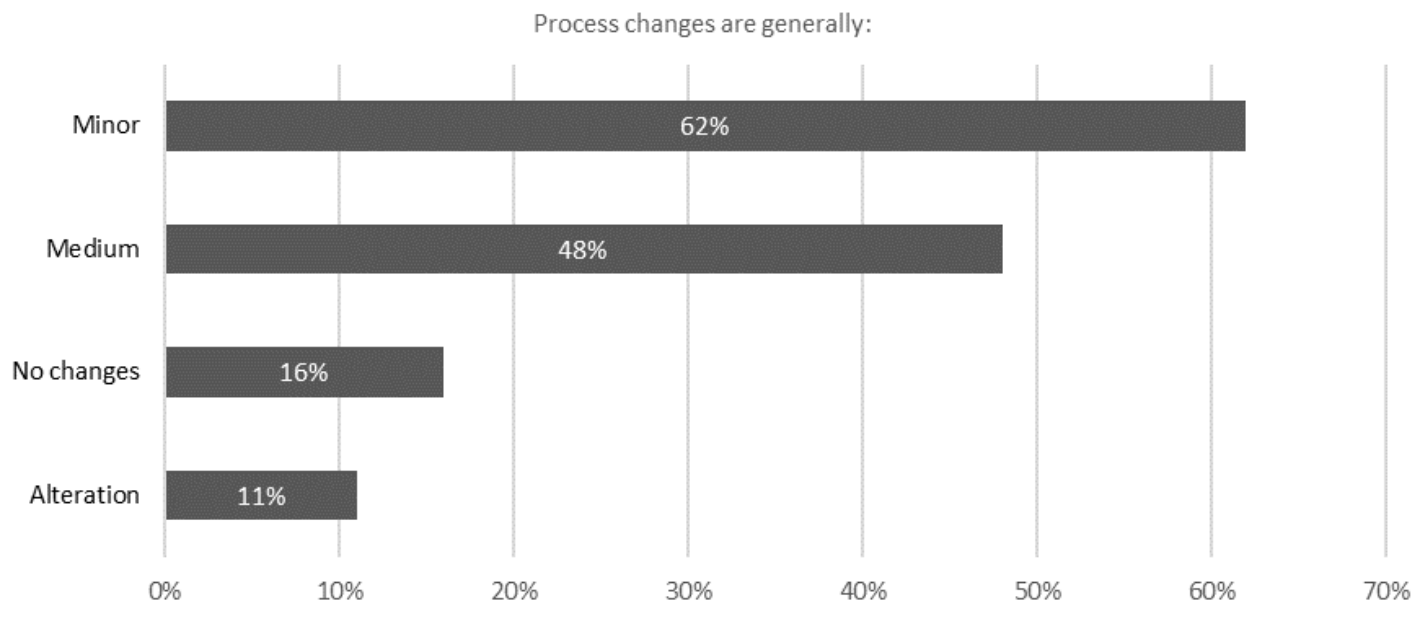

Key: The sum of the values does not equal $100 \%$ as the respondents have an option to check several answers to the same question

Fig. 11. Types of changes in business processes introduced prior to the robotic automation thereof [N $=238]$

Source: compiled on the basis of own research

In the vast majority of the organizations surveyed robotic process automation is implemented based on the agile approach or its variants - as indicated by as many as $85 \%$ of the respondents in total (see fig. 12). The overwhelming minority use the classic approach - employed only by $15 \%$ of the organizations. Thanks to the use of the agile approach and the direct involvement of the business in robotic automation, the time needed to achieve business benefits is much shorter than in case of using the classic process automation methods.

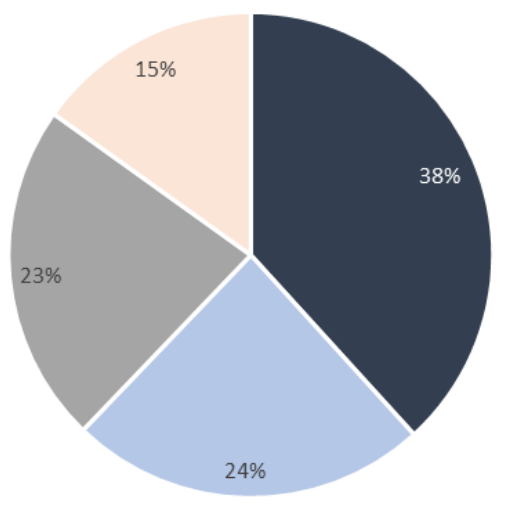

\footnotetext{
- "Hybrid approach" (agile + classic) with agile more prevalent

" "Fully agile" approach, developed based on Scrum or similar methodology

" "Hybrid approach" (agile + classic) with classic more prevalent

"Classic" approach, so-called Waterfall
}

Fig. 12. Methodology applied to implement robotic process automation by the enterprises surveyed $[\mathrm{N}=238]$ Source: compiled on the basis of own research 
As shown in fig. 13, robotic process automation is viewed as an extremely significant undertaking by the majority of the organizations surveyed. This is demonstrated by the fact that most often the works on robotic process automation at enterprises was initiated at the organizations surveyed by the company's management board (44\% of the respondents gave such an answer), and only at $13 \%$ of the enterprises the initiative was a bottom-up approach - coming from the workforce.
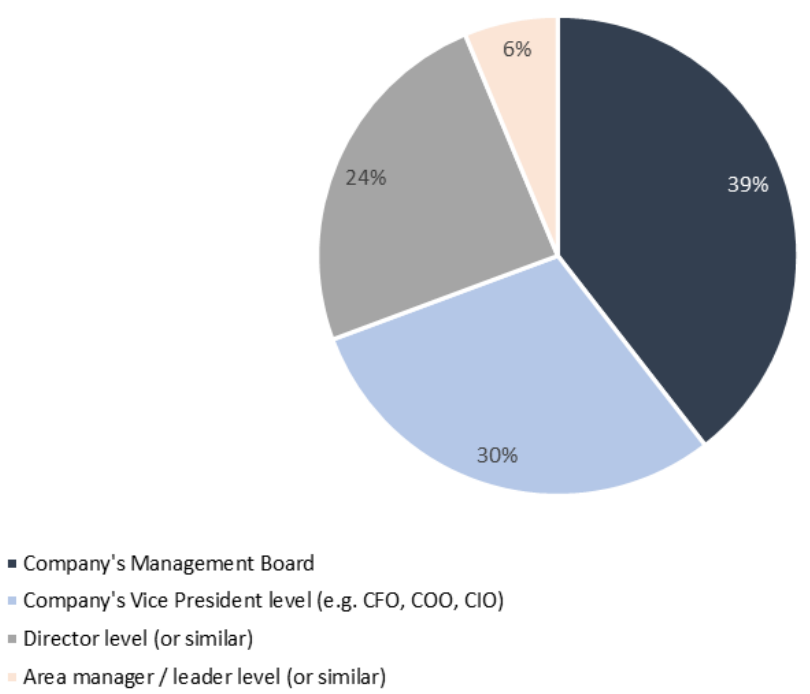

Fig. 13. Initiators of the works on robotic process automation at enterprises [ $\mathrm{N}=238]$ Source: compiled on the basis of own research

Based on the analysis of the answers related to the area where robotic process automation is applied at enterprises, it is clear that the broadly understood finance sphere - accounting, reporting, settlements, controlling and reporting - is the dominant application area (see fig. 14). In addition, software robots are applied in HR, payroll and IT. These indications are in line with other literature research. It is worth pointing out, however, that robotic process automation is also beginning to be applied with respect to customer service - both at the stage of marketing and sales, as well as post-sales service or debt collection. The question regarding the robotic process automation application areas was partially open-ended in the questionnaire and the respondents were also able to indicate other areas of its use. Individual respondents indicated that, additionally, robotic process automation is used at their enterprises in such areas as logistics, master data management and production. 


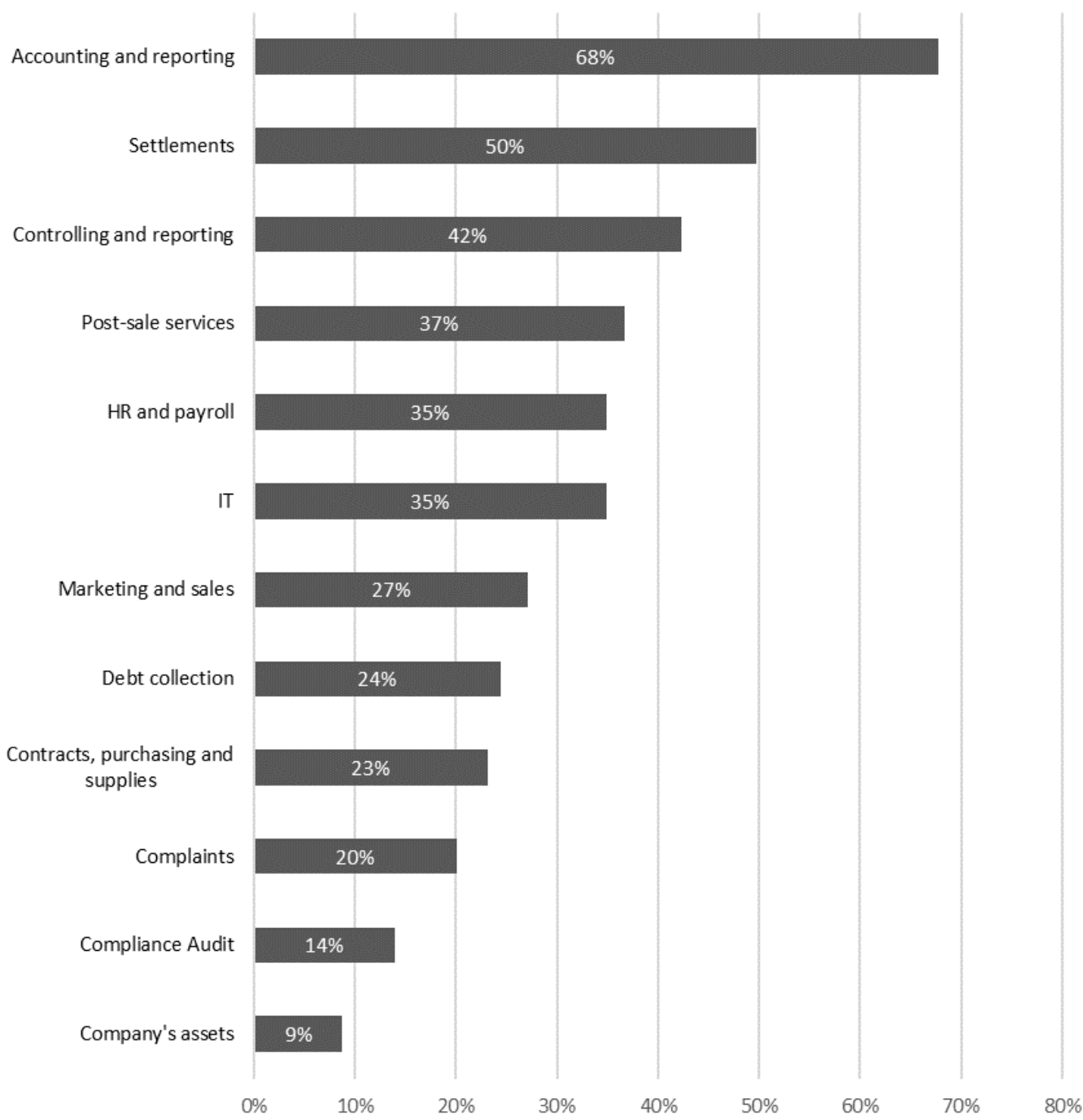

Fig. 14. Organizational units where software robots are used $[\mathrm{N}=238]$

Source: compiled on the basis of own research

As part of the research conducted, the author also made an attempt to answer the question: what factors have an impact on the success of robotic process automation (see fig. 15). 
ENTREPRENEURSHIP AND SUSTAINABILITY ISSUES

ISSN 2345-0282 (online) http://jssidoi.org/jesi/

2021 Volume 8 Number 4 (June)

http://doi.org/10.9770/jesi.2021.8.4(7)

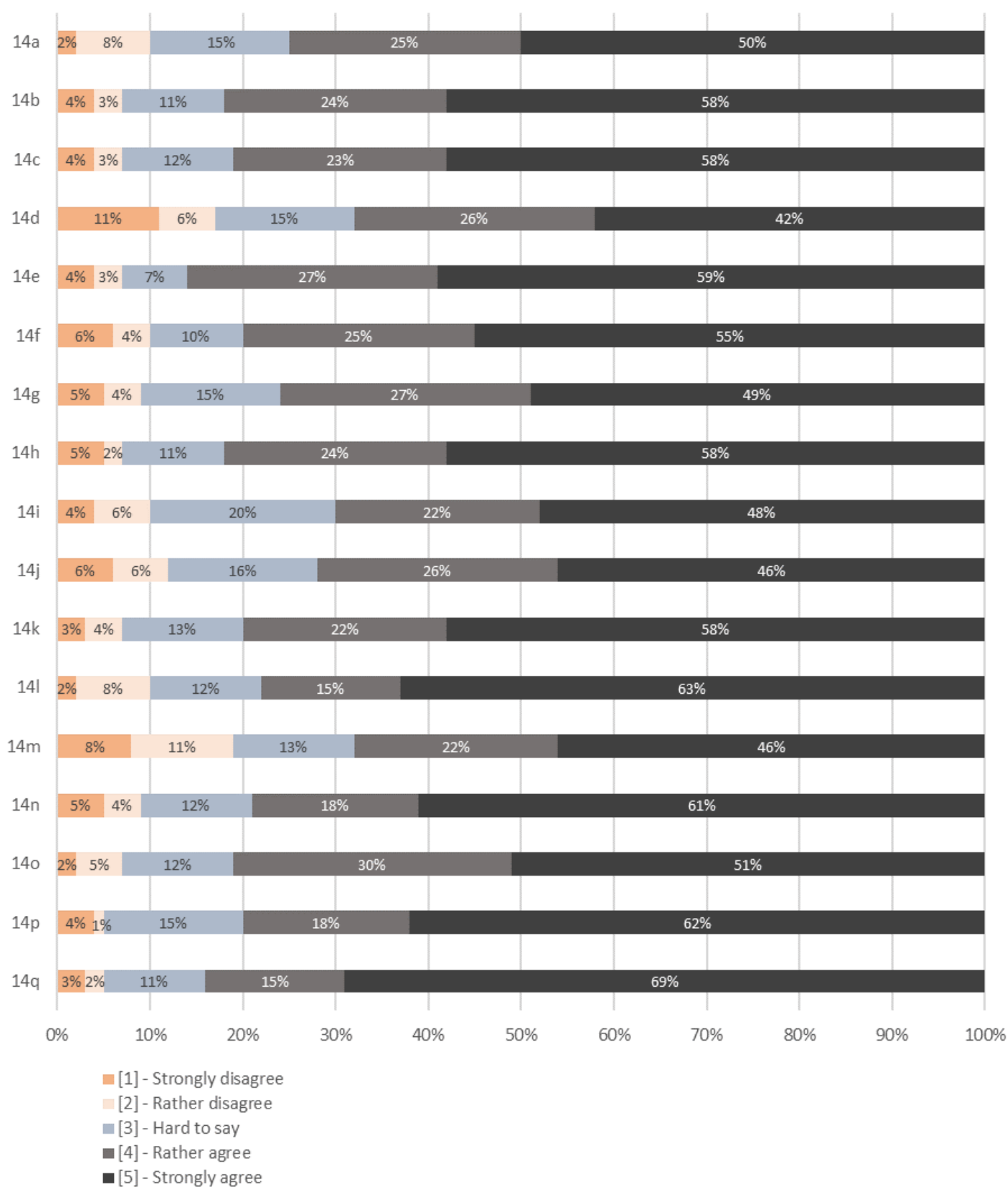

Key: Central measure (Median ) 50/50 of the distribution of answers for the individual items in the descending order: $14 \mathrm{~b}=$ Adopted organizational structure responsible for robotic process automation, $14 \mathrm{e}=$ Implemented principles of selecting and preparing processes to be robotically automated, $14 \mathrm{f}=$ Implemented principles of documenting and developing robots, $14 \mathrm{~h}=$ Building robotic process automation competences among the business personnel, 14k = Promoting a pro-innovative organizational culture among the workforce, $14 \mathrm{l}=$ Linking the goals of robotic proces automation with the strategic objectives of the company, $14 \mathrm{n}=$ Direct involvement of the management team in innovative activities (including robotic process automation), $140=$ Providing technological and management support from the consulting/IT companies, $14 \mathrm{p}=$ Well selected and interconnected set of robotic process automation tools (robotic process automation platform), $14 \mathrm{q}=$ Providing access to high quality data in a digital form that robots are working on, $14 \mathrm{a}=$ Developed robotic process automation strategy, $14 \mathrm{c}=$ Implemented principles of cooperation with IT/Security department $(\mathrm{ME}=5.0=$ Strongly agree $) .14 \mathrm{~d}=$ Implemented set of rules supporting the collection of structured knowledge of processes, $14 \mathrm{~g}=$ Implemented rules on how to make changes to the already robotically automated processes $/$ robots, $14 \mathrm{i}=$ Building competences on process management among the workforce, $14 \mathrm{j}=$ Agile organizational culture of an enterprise, $14 \mathrm{~m}=\mathrm{Monitoring}$ the progress of the implementation of robotic process automation by the management of the organization $(\mathrm{ME}=4.0=$ Rather agree $)$.

Fig. 15. Factors impacting the success of robotic process automation at a company [ $\mathrm{N}=238]$

Source: compiled on the basis of own research 


\section{ENTREPRENEURSHIP AND SUSTAINABILITY ISSUES}

ISSN 2345-0282 (online) http://jssidoi.org/jesi/

2021 Volume 8 Number 4 (June)

http://doi.org/10.9770/jesi.2021.8.4(7)

In accordance with the respondents' answers, the main factors that determine the success of robotic process automation include the adopted organizational structure responsible for robotic process automation (in particular, the establishment of a dedicated Center of Excellence), the implemented principles of selecting and preparing processes to be robotically automated (according to the subject matter literature, it is one of the key factors determining the success of the works carried out), c) building robotic process automation competences among the business personnel and promoting a pro-innovative organizational culture among the workforce. This is particularly important in view of the fact that mass robotic process automation changes the demand for competences among the workforce - the role of reproductive skills is diminishing in favor of algorithmic and process thinking, as well as soft skills. It is worth noting that the results obtained underscore a very important role of the organizational, cultural and competence related aspects as success factors, and not the technological ones (such as the choice of a robotic process automation tool). In addition, high quality digital data also plays an important role in the success of robotic process automation. Enterprises must remember this and implement mechanisms in the organization that ensure such data is available.

\section{Conclusions and further research}

As indicated by the research discussed, robotic process automation is a new subject for many companies. Undoubtedly, however, it will be one of the most important aspects of the digital transformation in the coming years, while the coronovirus pandemic and the economic turbulences related thereto will only accelerate activities in this area. This is confirmed by, among others, data analytics companies' forecasts, according to which robotic process automation (RPA) tools are currently the fastest growing group of digital transformation technologies on the IT market. According to Gartner the sales of solutions and services in this area rose $63.1 \%$ in 2019, as compared to 2018, coming in at USD 1.3 billion (Gartner, 2019). According to Forrester's analysts the value of RPA licenses and services sold is to reach USD 2.9 billion by 2021 (Clair and others, 2017). While according to Fortune Business Insight analytics company, the value of the RPA market is to reach USD 6.8 billion by the end of 2026 (Fortune Business Insight, 2020).

It is worth noting that the subject matter literature indicates that the RPA tools will now undergo intensive development, which may lead to the arrival of a new generation of such solutions (Anagnoste, 2018). It is believed that the future for this class of tools is Cognitive Automation, i.e. such automation where the software has gained the ability to operate effectively in unforeseen and uncertain situations. Cognitive automation uses algorithms and technological approaches derived from the field of artificial intelligence, such as natural language processing, text analysis and data mining, semantic technologies and machine learning (Marshall, Lambert, 2018, p. 200-210). This allows IT tools to autonomously evaluate and interpret knowledge. Additional elements, but important from the perspective of using cognitive automation, will include having sufficiently large data sets (required for machine learning processes) and access to high computing power. Therefore, cognitive automation will usually be applied in combination with big data tools and cloud computing. In addition, some of the data processed as part of advanced automation will come (at least for some time yet) from paper documents or photographs. For this reason, it is important to use software for automatic, optical character recognition (OCR), enriched with natural language processing capabilities (Wróblewska et al, 2018).

Cognitive automation will allow for providing totally new options for action (van der Aalst et al., 2018, p. 271). Firstly, software implementing this type of automation will have the ability to learn to react to the appearance of new objects and the development of new situations (Leopold, van der Aa, Reijers, 2018). Such cases have, thus far, been the weakness of classical automation. In the event of an unforeseen situation, the tools, at best, provided information about it, at worst - they took nondeterministic actions. Secondly: software that provides cognitive automation capabilities will be able to make complex decisions or such decisions that deal with ambiguities or seemingly competing alternatives. And thirdly and finally, this class of software will be able to detect and react to the situations where the risk and consequences of an error are high. 


\section{ENTREPRENEURSHIP AND SUSTAINABILITY ISSUES}

ISSN 2345-0282 (online) http://jssidoi.org/jesi/

2021 Volume 8 Number 4 (June)

http://doi.org/10.9770/jesi.2021.8.4(7)

In reference to the title of M. Ford's book, an assertion can be made that we are facing "The Rise of the Robots" (Ford, 2016).

Four research questions were defined in the introduction to the article. We managed to answer those questions in the course of the research process conducted. Referring to question RQ1 on the premises for implementing robotic process automation: enterprises, when planning activities in this area, mainly aim to reduce the costs of operations, relieve employees from routine activities, but also want to increase their innovations - be it in the product or process dimension. When analyzing the models applied to implement robotic process automation (question RQ2), an assertion can be made that the approach based on technology democratization is the dominating solution: most of the works in this area are carried out outside the IT department, usually by specialized centers of excellence (but there are also companies where robotic process automation is carried out directly by the business departments). Robotic process automation is usually implemented based on an agile or hybrid approach (a combination of agile and classic approaches, but with the emphasis on the classic one). Enterprises implementing robotic process automation are most often rebuilding processes to be robotically automated only to a limited extent. As for the areas in which software robots are used (question RQ3), the broadly understood support is the dominating area, including financial and HR departments. Some companies, however, are starting to use software robots in direct customer service (e.g. in sales, post-sale service, debt collection). According to the forecasts of the data analytics companies, this trend will intensify. According to the Gartner data analytics company, robots will also be used by $30 \%$ of enterprises to handle interactions with customers within the next 3-4 years (Gartner, 2020). In accordance with the respondents' answers, the main factors determining the success of robotic process automation include (question RQ4): a) adopted organizational structure responsible for robotic process automation (in particular, the establishment of the dedicated Center of Excellence), b) implemented principles of selecting and preparing processes to be robotically automated (it is one of the key factors determining the success of the works carried out, mentioned in the subject matter literature), c) building competences among the business personnel on robotic process automation and promoting a proinnovative organizational culture among the workforce. High quality digital data also plays a very important role in the success of robotic process automation.

The issues related to robotic process automation have found their place as part of the currently emerging interdisciplinary research area - robonomics. It is dealing with advanced automation technologies, in particular with robotic process automation, from the point of view of their impact on the economic and organizational aspects of the functioning of enterprises (Amiot, 2016), (Ivanov, 2017), as it is extremely important to make managers aware of the profound changes that robotic process automation will bring. Those enterprises that neglect the transfer of digital innovations related to robotic process automation to their organizations today may expect a significant deterioration of their market position in the coming years (Gölpek, 2015).

Therefore, the author intends to continue his research in the area of robotic process automation in the future. In particular, he is planning to examine how robotic process automation affects the business models of enterprises and the creation of digital innovations. The other area of the planned research work deals with the impact of robotic process automation on the enterprises' organizational structures and management mechanisms - in particular, on the role, scope of tasks and competencies of managers. 


\section{ENTREPRENEURSHIP AND SUSTAINABILITY ISSUES}

ISSN 2345-0282 (online) http://jssidoi.org/jesi/

2021 Volume 8 Number 4 (June)

http://doi.org/10.9770/jesi.2021.8.4(7)

\section{Acknowledgment}

This research was funded by the support of the Fundation Centre for Studies on Digital Government project "Advanced aspects of business process automation".

\section{References}

Aguirre, S., Rodriguez, A. (2017). Automation of a Business Process Using Robotic Process Automation (RPA): A Case Study. [in:] J. Figueroa-García, E. López-Santana, J. Villa-Ramírez, R. Ferro-Escobar (eds), "Applied Computer Sciences in Engineering. WEA 2017. Communications in Computer and Information Science”, Vol. 742, Springer, Cham, pp. 65-71.

Amiot, M. (2016). Robonomics - How automation will change work. Research Briefing, Oxford Economics, Retrieved August 31 , 2020 from URL https://www.oxfordeconomics.com/publication/download/295191.

Anagnoste, S. (2018). Robotic Automation Process - The operating system for the digital enterprise. Proceedings of the 12th International Conference on Business Excellence, De Gruyter Open, 12(1), pp. 54-69. https://doi.org/10.2478/picbe-2018-0007.

Asatiani, A., Penttinen, E. J. (2016). Turning robotic process automation into commercial success - Case OpusCapita. Journal of Information Technology Teaching Cases, 6(2), pp. 67-74.

Belz, G., Cyfert, S., Czakon, W., Dyduch, W., Latusek-Juraczak, D., Niemczyk, J., Sopinska, A., Szpitter, A., Urbaniak M., Wiktorow, J. (2019). Subdyscypliny $w$ naukach o zarzadzaniu i jakosci 2.0 (Subdisciplines in management and quality sciences 2.0). Komitet Nauk Organizacji i Zarzadzania Polskiej Akademii Nauk (Organization and Management Sciences Committee of the Polish Academy of Sciences). Retrieved August 31, 2020 from URL http://www.knoiz.pan.pl/images/stories/pliki/pdf/Subdyscypliny_nauk_o_zarzdzaniu i_jakoci.pdf.

Berman, S. (2012). Digital transformation: opportunities to create new business models. Strategy \& Leadership, $40(2)$, pp. 16-24.

Clair, C., Cullen, A., King, M. (2017). The RPA Market Will Reach \$2.9 Billion By 2021. Forrester. Retrieved August 31, 2020 from URL https://www.forrester.com/report/The+RPA+Market+Will+Reach+29+Billion+By+202/.

Eikebrokk, T., Olsen, D. (2020). Robotic Process Automation and Consequences for Knowledge Workers; a Mixed-Method Study. Lecture Notes in Computer Science (LNCS), 12066 LNCSs, pp. 114 - 125. https://doi.org/10.1007/978-3-030-44999-5_10.

Fersht, P., Gupta, S., Christopher, E. (2019). RPA is dead. Long live Integrated Automation Platforms, HfS Research, Retrieved August 31, 2020 from URL https://www.horsesforsources.com/rpa-dead-integrated-automation-platforms 041519

Ford, M. (2018). Rise of the Robots: Technology and the Threat of a Jobless Future. New York:Basic Books, ISBN: 0465097537.

Fortune Business Insights. (2020). Robotic Process Automation - Market size, Share \& Industry Analysis. Retrieved August 31,2020 from URL https://www.fortunebusinessinsights.com/robotic-process-automation-rpa-market-102042.

Gartner. (2019). Robotic Process Automation Software Market Grew 63\% in 2018. Retrieved August 31, 2020 from URL https://www.gartner.com/en/newsroom/press-releases/2019-06-24-gartner-says-worldwide-robotic-process-automation-sof.

Gartner. (2020). Gartner's IT Automation Predictions for 2020. Retrieved August 31, 2020 from URL https://info.advsyscon.com/itautomation-blog/gartner-it-automation.

Gölpek, F. (2015). Service Sector and Technological Developments. Procedia - Social and Behavioral Sciences, 181(11), pp. 125-130.

Ivanov, S. (2017). Robonomics - principles, benefits, challenges, solutions. Yearbook of Varna University of Management, 10, pp. 283293.

Jarrahi, M. (2019). In the age of the smart artificial intelligence: AI's dual capacities for automating and informating work. Business Information Review, 36(4), pp. 178-187. https://doi.org/10.1177/0266382119883999/. 


\section{ENTREPRENEURSHIP AND SUSTAINABILITY ISSUES}

ISSN 2345-0282 (online) http://jssidoi.org/jesi/

2021 Volume 8 Number 4 (June)

http://doi.org/10.9770/jesi.2021.8.4(7)

Kedziora, D., Penttinen, E. (2020). Governance models for Robotic Process Automation: The case of Nordea Bank. Journal of Information Technology Teaching Cases, July, https://doi.org/10.1177/2043886920937022/

Kobayashi, T., Arai, K., Imai, T., Watanabe, T. (2019). RPA Constitution Model for Consumer Service System based on IoT, 2019 IEEE 23rd International Symposium on Consumer Technologies, ISCT 2019, art. no. 8901009, pp. 82-86. https://doi.org/10.1109/ISCE.2019.8901009

Lacity, M., Willcocks, L. (2016). Robotic Process Automation at Telefonica O2. MIS Quarterly Executive, 15(1), pp. 21-35.

Lacity, M., Willcocks, L. (2017). Robotic Process Automation and Risk Mitigation: The Definitive Guide. United Kingdom: Steve Brookes Publishing, ISBN 978-0995682030.

Lacity, M., Willcocks, L. (2018). Robotic Process and Cognitive Automation: The Next Phase. United Kingdom:Steve Brookes Publishing, ISBN 978-0995682016.

Leopold, H., van der Aa, H., Reijers, H.A. (2018). Identifying candidate tasks for robotic process automation in textual process descriptions. Lecture Notes in Business Information Processing, 318, pp. 67-81.

Marshall, T., Lambert, S. (2018). Cloud-Based Intelligent Accounting Applications: Accounting Task Automation Using IBM Watson Cognitive Computing. Journal of Emerging Technologies in Accounting, 15(1), pp. 199-215.

Nambisan, S., Lyytinen, K., Majchrzak, A., Song, M. (2017). Digital innovation management: reinventing innovation management research in a digital world. MIS Quarterly, 41(1), pp. 223-238.

Nauwerck, G., Cajander, Å. (2019). Automatic for the People: Implementing Robotic Process Automation in Social Work. Proceedings of the 17th European Conference on Computer-Supported Cooperative Work: The International Venue on Practice-centred Computing and the Design of Cooperation Technologies - Demos and Posters, Reports of the European Society for Socially Embedded Technologies (ISSN 2510-2591), https://doi.org/10.18420/ecscw2019_p04.

Rifkin, J. (1994). The End of Work - The Decline of the Global Labor Force and the Dawn of the Post-Market Era, New York: Tarcher, ISBN: 978-0874777796.

Shaw, R. D., Holland, P. Ch., Kawalek, P., Snowdon, B., Warboys, B. (2007). Elements of a business process management system: theory and practice. Business Process Management Journal, 13(1), pp. 91-107.

Smith, T., Kim, J. (2015). A Review of Survey Data-Collection Modes: With a Focus on Computerizations. Sociological Theory and Methods, 30(2), pp. 185-200. Retrieved August 31, 2020 from URL http://gss.norc.org/Documents/reports/methodologicalreports/MR126.pdf.

Stolpe, A., Steinsund, H., Iden, J., Bygstad, B. (2017). Lightweight IT and the IT Function - Experiences from Robotic Process Automation in a Norwegian Bank. NOKOBIT, 25(1), Bibsys Open Journal Systems, ISSN 1894-7719.

Suri, V., Elia, M., van Hillegersberg, J. (2017). Software bots - The next frontier for shared services and functional excellence, Lecture Notes in Business Information Processing, 306, pp. 81-94.

van der Aalst, W., Bichler, M. P., Heinz, A. (2018). Robotic Process Automation, Business \& Information Systems Engineering, 60(4), pp. 269-272.

Varghese, F.C., Kumar, T.A. (2017). The impact of automation in IT industry: Evidences from India. International Journal of Advanced Research in Computer and Communication Engineering, 6, pp. 292-297.

Willcocks, L., Hindle, J., Lacity, M. (2020). Becoming Strategic with Robotic Process Automation. United Kingdom: Steve Brookes Publishing, ISBN 978-0-9956820-5-4.

Wróblewska, A., Stanislawek, T., Prus-Zajaczkowski, B., Garncarek, L. (2018). Robotic Process Automation of Unstructured Data with Machine Learning, Position Papers of the Federated Conference on Computer Science and Information Systems, pp. 9-16. $\underline{\text { https://doi.org/10.15439/2018F373 }}$ 


\section{ENTREPRENEURSHIP AND SUSTAINABILITY ISSUES}

ISSN 2345-0282 (online) http://jssidoi.org/jesi/

2021 Volume 8 Number 4 (June)

http://doi.org/10.9770/jesi.2021.8.4(7)

Andrzej SOBCZAK (PhD) is a Professor at Warsaw School of Economics, Collegium of Economic Analysis, Poland. He is the manager of the IT Manangement Unit operating as a part of the Institute of Information Systems and Digital Economy. He has completed internships at the University of Waterloo (Canada), University of Stratclyde (Scotland), University of Manchester (Great Britain), University of York (Great Britain), Trinity College (Ireland), Center of Health Informatics (Ireland). He has been dealing with digital transformation and digital innovation for several years. His research interests are currently focused on the advanced automation and robotic automation of business processes and services. Research interests: digital transformation, robotic process automation, digital technology adoption, digital innovation.

ORCID ID: $\underline{\text { https://orcid.org/0000-0002-1271-1251 }}$

Make your research more visible, join the Twitter account of ENTREPRENEURSHIP AND SUSTAINABILITY ISSUES: @Entrepr69728810

Copyright (C) 2021 by author(s) and VsI Entrepreneurship and Sustainability Center

This work is licensed under the Creative Commons Attribution International License (CC BY).

http://creativecommons.org/licenses/by/4.0/

(C) (i) Open Access 